\title{
OFICINA DO "MUNDO QUILOMBOLA": CULTURA NO MUSEU DE HISTÓRIA NATURAL DO SUL DO ESTADO DO ESPÍRITO SANTO (MUSES)
}

\author{
Caroline Palacio de Araujo ${ }^{1}$ \\ Vanessa Fagundes Campos ${ }^{2}$ \\ Aline Tintori Mantovani ${ }^{3}$ \\ Janete Valani ${ }^{4}$ \\ Kênia Rezende ${ }^{5}$ \\ Kalia Dável Grecco ${ }^{6}$ \\ Anderson Lopes Peçanha ${ }^{7}$ \\ Elias Terra Werner ${ }^{8}$
}

\begin{abstract}
Resumo: O "Mundo quilombola" foi uma das oficinas realizadas no Museu de História Natural do Sul do Estado do Espírito Santo (MUSES) durante a $14^{\circ}$ Semana Nacional de Museus, que teve como tema "Museus e paisagens culturais". Esta semana acontece anualmente para comemorar o Dia Internacional de Museus, 18 de maio, quando museus brasileiros, convidados pelo IBRAM, desenvolvem uma programação especial em prol dessa data. Esta oficina teve como objetivo mostrar aos visitantes um pouco sobre a história e as tradições dos remanescentes de quilombolas, com ênfase na comunidade quilombola de Monte Alegre, localizada na zona rural do distrito de Pacotuba, sendo este pertencente ao município de Cachoeiro de Itapemirim-ES. Os visitantes se mostraram interessados e entusiasmados com a cultura dos quilombolas e confecção das pulseiras. A oficina proporcionou um momento de prazer e de aprendizado.
\end{abstract}

Palavras-chave: Oficina; História; Escravidão; Cultura.

\footnotetext{
${ }^{1}$ Ciências Biológicas/Universidade Federal do Espírito Santo, Brasil. E-mail: carolinepalacio@yahoo.com.br.

2 Ciências Biológicas/Universidade Federal do Espírito Santo, Brasil. E-mail: vanessafcampos@outlook.com.

${ }^{3}$ Ciências Biológicas/Universidade Federal do Espírito Santo, Brasil. E-mail: alinetintori@hotmail.com.

${ }^{4}$ Ciências Biológicas/Universidade Federal do Espírito Santo, Brasil. E-mail: janetevalani@gmail.com.

${ }^{5}$ Ciências Biológicas/Universidade Federal do Espírito Santo, Brasil. E-mail: kenia.rezende@yahoo.com.br.

${ }^{6}$ Ciências Biológicas/Universidade Federal do Espírito Santo, Brasil. E-mail: kaliagrecco@hotmail.com.

7 Departamento de Biologia/Universidade Federal do Espírito Santo, Brasil. E-mail: lopes.pecanha@gmail.com.

${ }^{8}$ Departamento de Biologia/Universidade Federal do Espírito Santo, Brasil. E-mail: eliaswerner12@gmail.com.
} 